\title{
Comparative Analysis of Biotissue Laser Resection Using Strongly Absorbing Optical Fiber Tips
}

\author{
Daria S. Kuznetsova1 ${ }^{*}$, Maria M. Karabut ${ }^{1}$, Vadim V. Elagin', Maria A. Shakhova ${ }^{2}$, \\ Vladimir I. Bredikhin ${ }^{3}$, Olga S. Baskina4, Ludmila B. Snopova4, Andrey V. Shakhov5, \\ Vladislav A. Kamensky ${ }^{3}$ \\ ${ }^{1}$ Lobachevsky State University of Nizhni Novgorod, National Research University, Nizhny Novgorod, Russia \\ ${ }^{2}$ Otolaryngology Clinic, N.A. Semashko Nizhny Novgorod Regional Clinical Hospital, Nizhny Novgorod, Russia \\ ${ }^{3}$ Institute of Applied Physics of the Russian Academy of Sciences, Nizhny Novgorod, Russia \\ ${ }^{4}$ Central Research Laboratory, Nizhny Novgorod State Medical Academy, Nizhny Novgorod, Russia \\ ${ }^{5}$ The Department of Otorhinolaryngology, Nizhny Novgorod State Medical Academy, Nizhny Novgorod, Russia \\ Email: ${ }^{*}$ daria.s.kuznetsova@gmail.com
}

Received 1 December 2014; accepted 15 December 2014; published 13 January 2015

Copyright (C) 2015 by authors and Scientific Research Publishing Inc.

This work is licensed under the Creative Commons Attribution International License (CC BY). http://creativecommons.org/licenses/by/4.0/

(c) (†) Open Access

\begin{abstract}
We present a laser resection technique to be used when biotissue is heated by laser radiation to the temperature of material softening and then moved apart by the lateral edge of the optical fiber with a strongly absorbing tip. The absorbing tip allows the decrease in the power of effective cutting of the laser scalpel at the wavelength of $0.97 \mu \mathrm{m}$. And it changes the resection speed as well as the characteristics of the damage of the tissues adjacent to the incision in experiments on model media and experimental animals.
\end{abstract}

\section{Keywords}

Laser Resection, Silica Fibers, Strongly Absorbing Coating, Histology

\section{Introduction}

The exposure of biotissue to laser radiation has been studied since the advent of lasers and a wide arsenal of powerful sources of optical radiation has been created by now [1] [2]. Complex structure of biological objects ${ }^{*}$ Corresponding author.

How to cite this paper: Kuznetsova, D.S., Karabut, M.M., Elagin, V.V., Shakhova, M.A., Bredikhin, V.I., Baskina, O.S., Snopova, L.B., Shakhov, A.V. and Kamensky, V.A. (2015) Comparative Analysis of Biotissue Laser Resection Using Strongly Absorbing Optical Fiber Tips. Optics and Photonics Journal, 5, 1-5. http://dx.doi.org/10.4236/opj.2015.51001 
and diversity in the nature of their interaction with light determine the need to use various types of lasers and laser systems in surgery. The laser surgery research was especially intense in the 1990s [3] and it might seem that currently it has passed over from the stage of studying exposure modes to development of medical technologies [4] [5]. However, there is still a vast field for research in this field. For example, one of the basic elements of a laser scalpel is optical fiber that is not only a means for radiation delivery to the object under study but is also a knife that contacts the biotissue. The silica fiber with low attenuation $(20 \mathrm{~dB} / \mathrm{km})$ developed by the US company Corning in 1970 was a technological breakthrough. Nowadays, cylindrical optical fibers are widely used as a transmission medium in optical communication systems and for biomedical applications. In laser surgery, multimode silica fibers transmitting laser radiation in a wide wavelength range from $300 \mathrm{~nm}$ to $2400 \mathrm{~nm}$ are employed. Silica fibers are highly technological and handy for laser surgery. The cutting part of the laser scalpel is usually the tip of a silica fiber glass core cleared from the cladding layer. Optical fiber is mechanically flexible, Its silica core is very strong, with the tip resistant to high temperatures arising at carbonization of biotissue exposed to a laser scalpel. The standard average power of a laser scalpel is several Watts per a fiber tip diameter of $550 \mu \mathrm{m}$.

To improve the exposure conditions at the tissue-fiber interface various focusing gadgets [6]-[8] and special tips for temperature control in the interaction region [9] are employed. Optimal wavelengths and modes of laser operation have been found for some kinds of biotissues, cartilages first of all. At the same time, there are still many unsolved problems solution of which demands elaboration of new surgical methods and tools [10] [11]. We developed a technique of laser resection [12], when biotissue was heated by laser radiation and moved apart by the lateral edge of the optical fiber, and have modified it by adding to the fiber a strongly absorbing tip. Conventional techniques imply usage of radiation absorption in the medium and, correspondingly, radiation wavelengths close to the peaks of water absorption; whereas we propose to use strong absorption in a special coating of the silica fiber tip used as the incision surface.

In this work we present the first results of utilizing such tips that enable realizing unified modes of exposure for silica fiber lasers operating at arbitrary wavelengths.

\section{Materials and Methods}

We used the laser scalpel LCP-0,97/10 (Azor LLC, Russia) operating in the mode of cw generation at the wavelength of $0.97 \mu \mathrm{m}$. The radiation was delivered to tissue by replaceable silica fibers $550 \mu \mathrm{m}$ in diameter. Preliminary assessment of the cutting capability of the scalpel was done ex vivo on chicken muscular tissue. Three modes of tissue incision were investigated: with a clear (without any coating) operating fiber tip, with a carbon initiated tip and a tip with a strongly absorbing coating (SAC). Carbonic tablets developed by Dental Photonics, Inc. (USA) were used for initiation following the respective procedure [13]. We propose to use a SAC that is a mixture of polymethyphenylsiloxane resin and graphite powder with fractions less than $0.5 \mu \mathrm{m}$. The fiber tip is initiated analogously to the Dental Photonics technique: an enamel drop is deposited on a glass surface (e.g., an object plate of a microscope) and the fiber tip is dipped into the drop (i.e., the enamel is applied on the optical fiber area of about $0.5 \mathrm{~mm}$ ).

For unifying the cuts we fabricated a tool permitting to make an incision on tissue with equal force of $0.44 \mathrm{H}$ (45 g) (Figure 1). The operating fiber tip was brought to the tissue surface and pressed 1 - $2 \mathrm{~mm}$ into it; the incision was made by the lateral edge of the scalpel. The cutting capability of the laser scalpel was assessed by several parameters:

1. Speed of tissue cutting.

2. Incision width.

3. Incision depth.

4. Width of the coagulation zone.

5. Tissue carbonization in the incision.

The chosen parameters were tested on the skin of nonlinear white male rats. Prior to testing, the animals were depilated in areas to be studied and then anaesthetized with Zolethyl solution with a dose of $50 \mathrm{mg} / \mathrm{kg}$ dose. The incision was handmade by a laser scalpel under the following conditions:

1. A clear fiber tip, the output power of $3 \mathrm{~W}$.

2. A clear fiber tip, the output power of $7 \mathrm{~W}$.

3. A SAC tip, the output power of $3 \mathrm{~W}$. 


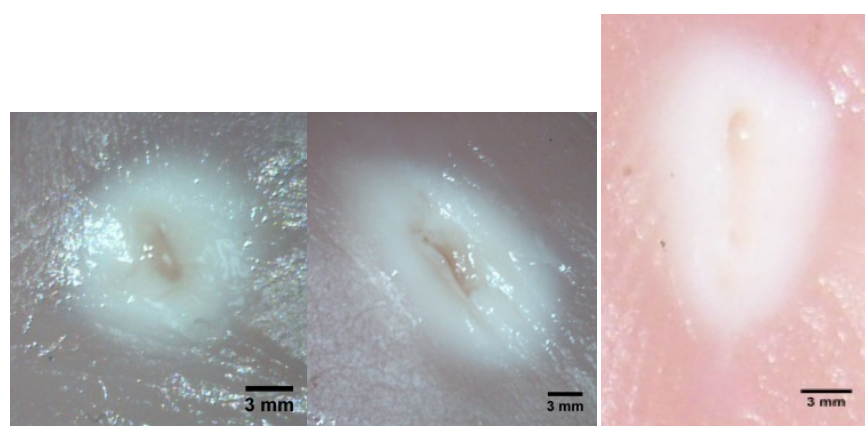

(a)

(b)

(c)

Figure 1. Tissue incisions made by a clear fiber tip at the laser output power of $3 \mathrm{~W}$ (a), $4 \mathrm{~W}$ (b), and $7 \mathrm{~W}$ (c).

4. A carbon initiated tip, the output power of $3 \mathrm{~W}$.

After making the incision, the injury was documented by means of the USB-microscope MicMed $2000 \mathrm{R}$. Also, the incision depth and width were measured. After that, the specimens were taken for a histological study and fixed with $10 \%$ formalin. 5 - $7 \mu \mathrm{m}$ thickness histological sections oriented cross to incision were made by microtome Leica SM 2000. Van Gieson's stain was used for assessment of collagen fiber state after making the incision. Study of structural changes of skin was carried out by light microscope Leica DM 1000.

\section{Results}

\subsection{Laser Radiation Exposure of Samples ex Vivo by a Silica Fiber Tip Contacting Them with Dosed Pressure}

The preliminary study on ex vivo samples of chicken muscular tissue showed that the speed of tissue cutting by a clear fiber tip was $4 \mathrm{~mm} / \mathrm{min}$ at the output power of $3 \mathrm{~W}$. A $2 \mathrm{~mm}$-wide coagulation area was formed around the incision. No tissue carbonization was observed (Figure 1(a)). As the power was increased up to $4 \mathrm{~W}$, the speed of tissue cutting increased up to $11.4 \mathrm{~mm} / \mathrm{min}$, and the width of the coagulation area reduced to $1.1-1.3 \mathrm{~mm}$. At the same time, the incision depth increased up to $2.5 \mathrm{~mm}$ and the tissue started to carbonize (Figure 1(b)). The tissue incision made by the scalpel with the output power of $7 \mathrm{~W}$ was $2 \mathrm{~mm}$ wide and $2 \mathrm{~mm}$ deep. The coagulation area was $6.8 \mathrm{~mm}$ and the cutting speed was $22 \mathrm{~mm} / \mathrm{min}$.

The optical fiber with a tip initiated by carbon had a higher cutting speed. It amounted to $9.9 \mathrm{~mm} / \mathrm{min}$ at the output power of $2 \mathrm{~W}$ and to $16.2 \mathrm{~mm} / \mathrm{min}$ at the output power of $3 \mathrm{~W}$. The width of the incision and of the coagulation area at $2 \mathrm{~W}$ was $1.7 \mathrm{~mm}$ and $1.8 \mathrm{~mm}$, respectively, and the incision depth was $3 \mathrm{~mm}$ (Figure 2(a)). With the increase of power up to $3 \mathrm{~W}$, the incision width increased up to $2 \mathrm{~mm}$, the coagulation area decreased down to $1.3 \mathrm{~mm}$, while the incision depth remained unchanged (Figure 2(b)).

The optical fiber with a SAC tip at the output power of $2 \mathrm{~W}$ produced a tissue incision $1.2 \mathrm{~mm}$ wide with a coagulation area of $1.3 \mathrm{~mm}$. The depth of such an incision varied from $1.5 \mathrm{~mm}$ to $2 \mathrm{~mm}$ (Figure 3(a)). The cutting speed for these parameters was $11 \mathrm{~mm} / \mathrm{min}$. With the increase of the output power to $3 \mathrm{~W}$, the cutting speed increased up to $30 \mathrm{~mm} / \mathrm{min}$ and the coagulation area increased only insignificantly, to $1.5 \mathrm{~mm}$.

When tissue incisions were made in vivo, good coagulation was obtained for all the studied parameters. Hemorrhage was not observed in any case. Tissue carbonization area was formed in all the studied regimes. The incision depth did not depend on the used regime and was about $1 \mathrm{~mm}$, whereas the incision width was variable. The dissections made with a clear fiber tip had the smallest width: $1.1 \mathrm{~mm}$ at the output power of $3 \mathrm{~W}$ and 1.3 $\mathrm{mm}$ at $7 \mathrm{~W}$. When the operating tip of the laser scalpel had a strongly absorbing coating, the incision width increased. The use of tip coatings resulted in formation of a $1.5 \mathrm{~mm}$-wide incision at the output power of the laser scalpel of $3 \mathrm{~W}$; and in the case of a carbon initiated fiber tip, an incision with a width of $2.2 \mathrm{~mm}$ was formed at the same output power.

An important feature of a strongly absorbing coating is its stability to mechanical and laser action. The carbon initiated coating almost disappeared 5 minutes after the beginning of laser cutting, whereas SAC lost its efficiency in 15 minutes. 


\subsection{Laser Radiation Exposure of Laboratory Animals by a Surgeon-Manipulated Silica Fiber Tip}

It was shown that incisions made by optical fiber tips with different coatings had same type of the structural changes typical for thermal injury.

Carbonization of the epithelial layer was observed after skin treatment by laser scalpel with clear fiber tip. Dermis in subepithelial layer was coagulated and had evident induration. The structure of collagen fibers was not defined. Cells and their nuclei were destroyed. Under the dense zone located area of dermis that saved structural feature, but it had not sharp outline. In this area collagen fibers were swelled and homogenized. Hemolysis of erythrocyte was detected in vessels. Tissue had features of dehydration such as rarefaction of dermis and delamination of connective tissue components around hair follicles. Injuries had following size: width was $2085 \mu \mathrm{m}$, depth—from $278 \mu \mathrm{m}$ to $901 \mu \mathrm{m}$ (Figure 4(a)).

Incisions made by optical fiber tips with SAC had area of epithelium carbonization that joined with area of coagulation changes. The coagulation area was not evident compared with same area in case of clear fiber. Region of swelling and homogenization had sharp outline. Features of dehydration were clearer. Width of injuries was $1946 \mu \mathrm{m}$, depth—from $278 \mu \mathrm{m}$ to $417 \mu \mathrm{m}$ (Figure 4(b)).

Carbonization and exfoliation of epidermis were found after incision made by optical fiber with a layer of coal. The zone of coagulation in the region adjacent to the epidermis had a honeycomb structure. Also this zone had a not sharp outline with swelling and homogenization of collagen fibers. There were not pronounced signs

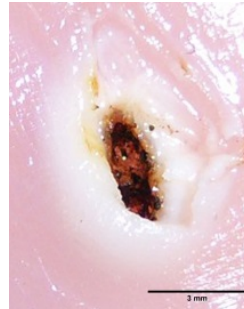

(a)

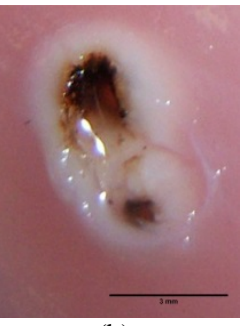

(b)

Figure 2. Tissue incisions made by a carbon initiated fiber tip at the output power of $2 \mathrm{~W}$ (a) and $3 \mathrm{~W}$ (b).

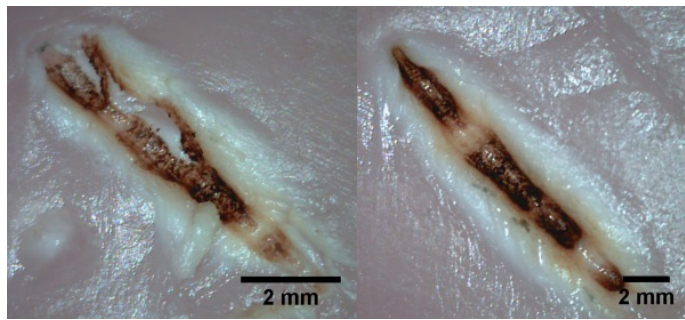

(a)

(b)

Figure 3. Tissue incisions made by a SAC fiber tip at the output power of $2 \mathrm{~W}$ (a) and $3 \mathrm{~W}$ (b).

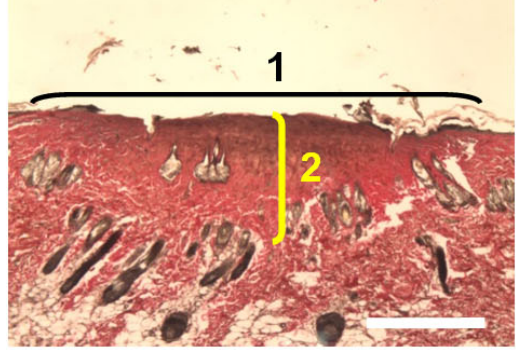

(a)

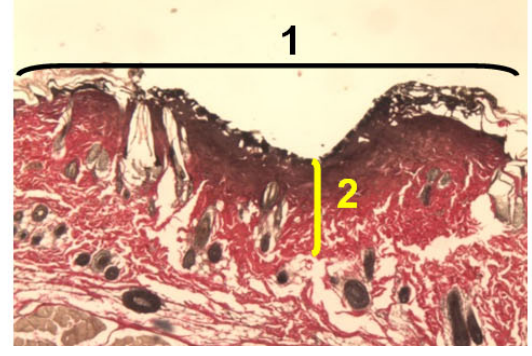

(b)

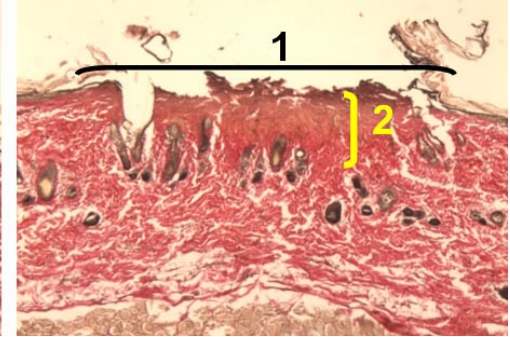

(c)

Figure 4. Histology image of mouse skin on exposure to radiation of silica fiber at $0.97 \mu \mathrm{m}$ : (a) clear fiber tip; (b) SAC fiber tipc) carbon initiated fiber tip. Van Giesonstaining. 
of dehydration of surrounding tissue. Width of injuries was $1932 \mu \mathrm{m}$, depth—from $278 \mu \mathrm{m}$ to $695 \mu \mathrm{m}$ (Figure $4(\mathrm{c}))$.

On exposure to laser radiation by optical fiber tips with different coatings the structural changes in the samples were of the same type. Burn destruction of epidermis was observed in the skin. Visible coagulation morphological changes were revealed in the derma. The properties of collagen fibers under the coagulation area underwent changes: collagen fiber swelling and sections of destruction in the form of dissection and rupture were visualized.

Under exposure to laser radiation with a power of $7 \mathrm{~W}$ the changes were like in the case of $3 \mathrm{~W}$ power, but more pronounced. Note that the coagulation area is visually denser on exposure to the radiation of $7 \mathrm{~W}$.

\section{Conclusion}

Coating of optical fibers enables obtaining new modes of biotissue exposure to radiation. The performed research demonstrated that a laser scalpel with a fiber tip having a strongly absorbing coating operating with the output power of $3 \mathrm{~W}$ proved to be most efficient for making contact incisions. It provided maximum tissue cutting speed and small coagulation area and, consequently, less thermal damage of the surrounding tissues. The morphological study of the laser incision area showed that the depth of thermally damaged region in the center of the exposure area decreased from $901 \mu \mathrm{m}$ with the use of a clear fiber tip to $417 \mu \mathrm{m}$ in the case of a resin and carbon coating. This coating is more stable to combined mechanical and laser action.

\section{Acknowledgements}

The work was supported by the RSF grant "The Use of Laser Induced Nonequilibrium Processes in Medical Technologies” No. 14-15-00840 dated 20 May, 2014.

\section{References}

[1] Jacques, S.L. (1992) Laser-Tissue Interactions: Photochemical, Photothermal and Photomechanical. Surgical Clinics of North America, 72, 531-558.

[2] Murray, A. and Mitchell, D.C. (1992) Wood RFM. Lasers in Surgery. British Journal of Surgery, 79, 21-26. http://dx.doi.org/10.1002/bjs.1800790106

[3] Letokhov, V.S. (1985) Laser Biology and Medicine. Nature, 316, 325-330. http://dx.doi.org/10.1038/316325a0

[4] Romeo, U., Libotte, F., Palaia, G., Del Vecchio, A., Tenore, G., Visca, P., Nammour, S. and Polimeni, A. (2012) Histological in Vitro Evaluation of the Effects of Er:YAG Laser on Oral Soft Tissues. Lasers in Medical Science, 27, 749-753. http://dx.doi.org/10.1007/s10103-011-0969-z

[5] Lopes, B.M., Theodoro, L.H., Melo, R.F., Thompson, G.M. and Marcantonio, R.A. (2010) Clinical and Microbiologic Follow-Up Evaluations after Non-Surgical Periodontal Treatment with Erbium:YAG Laser and Scaling and Root Planing. Journal of Periodontology, 81, 682-691. http://dx.doi.org/10.1902/jop.2010.090300

[6] Verdaasdonk, R.M. and Borst, C. (1991) Ray Tracing of Optically Modifiedfiber Tips. 1: Spherical Probes. Applied Optics, 30, 2159-2171. http://dx.doi.org/10.1364/AO.30.002159

[7] Stegmayer, T., Graser, R., Forster, W. and Hibst, R. (2012) Comparison of Different Focusing Fiber Tips for Improved Oral Diode Laser Surgery. Lasers in Surgery and Medicine, 44, 1-9.

[8] Melnik, I.S., Hibst, R., Fischer, M. and Flemming, G. (1993) New Modified Optical Fiber Tips for Medical Applications. Optical Engineering, 32, 227-232. http://dx.doi.org/10.1117/12.60737

[9] Verdaasdonk, R.M., Jansen, E.D., Holstege, F.C. and Borst, C. (1991) Mechanism of CW Nd:YAG Laser Recanalization with Modified Fiber Tips: Influence of Temperature and Axial Force on Tissue Penetration in Vitro. Lasers in Surgery and Medicine, 11, 204-212. http://dx.doi.org/10.1002/lsm.1900110303

[10] Havel, M., Betz, C.S., Leunig, A. and Sroka, R. (2014) Diode Laser-Induced Tissue Effects: In Vitro Tissue Model Study and in Vivo Evaluation of Wound Healing Following Non-Contact Application. Lasers in Surgery and Medicine, 46, 449-455. http://dx.doi.org/10.1002/lsm.22256

[11] Janda, P., Sroka, R., Baumgartner, R., Grevers, G. and Leunig, A. (2001) Laser Treatment of Hyperplastic Inferior Nasal Turbinates: A Review. Lasers in Surgery and Medicine, 28, 404-413. http://dx.doi.org/10.1002/lsm.1068

[12] Shakhov, A.V., Terentjeva, A.B., Kamensky, V.A., Snopova, L.B., Feldstain, F.I. and Sergeev, A.M. (2001) Optical Coherence Tomography Monitoring for Laser Surgery of Laryngeal Carcinoma. Journal of Surgical Oncology, 77, 253-259. http://dx.doi.org/10.1002/jso.1105

[13] http://altamls.com/applications/soft-tissue-surgery/how-top-surgery-works/ 
Scientific Research Publishing (SCIRP) is one of the largest Open Access journal publishers. It is currently publishing more than 200 open access, online, peer-reviewed journals covering a wide range of academic disciplines. SCIRP serves the worldwide academic communities and contributes to the progress and application of science with its publication.

Other selected journals from SCIRP are listed as below. Submit your manuscript to us via either submit@scirp.org or Online Submission Portal.
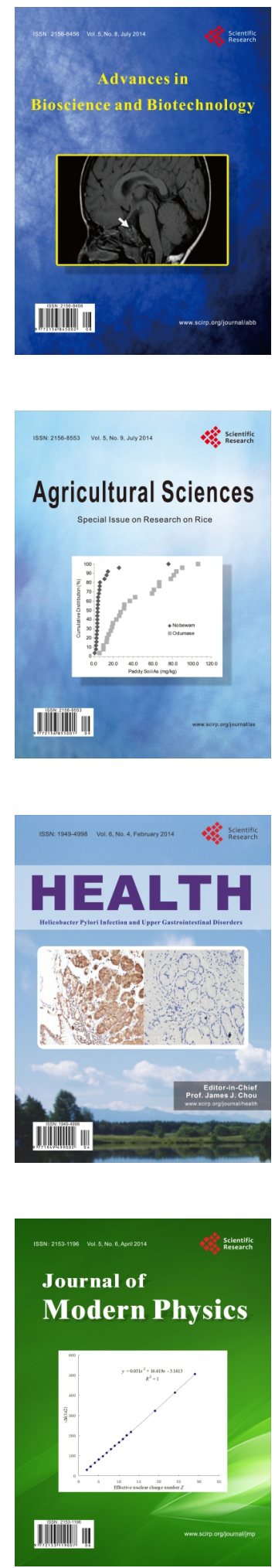
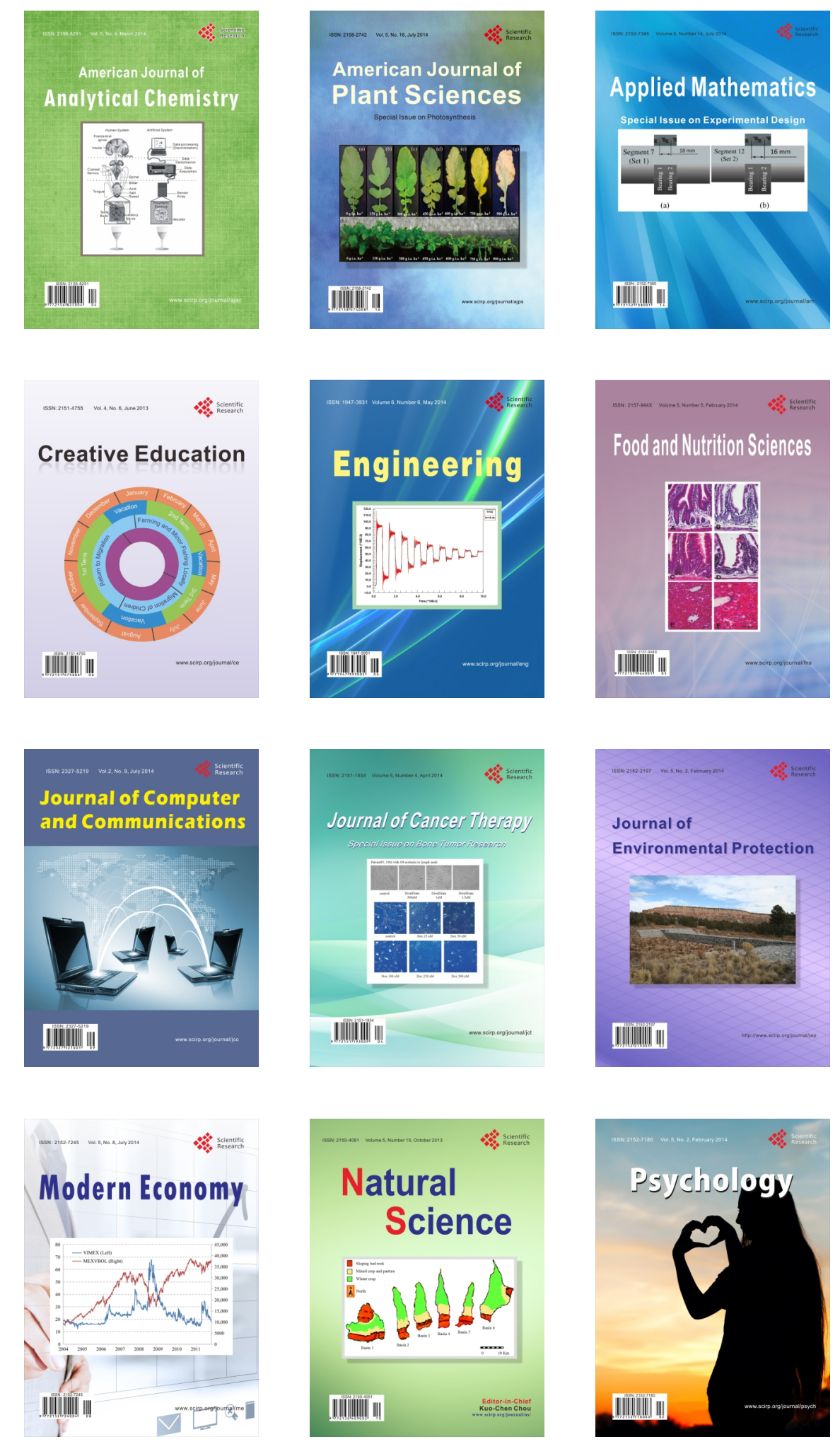